\title{
Quality of life outcomes in patients with localised renal cancer: a literature review
}

\author{
Sabrina H. Rossi ${ }^{1}$ (1) $\cdot$ Tobias Klatte $^{1,2}$ (1) $\cdot$ Grant D. Stewart ${ }^{1}$ (1)
}

Received: 30 April 2018 / Accepted: 18 July 2018 / Published online: 26 July 2018

(c) The Author(s) 2018

\begin{abstract}
Purpose Patients with localised renal cell carcinoma (RCC) can expect excellent oncologic outcomes. As such, there has been a shift towards maximising health-related quality of life (HRQoL). A greater understanding of HRQoL outcomes associated with different treatment options for RCC can facilitate patient-centred care, shared decision-making and enable cost utility analyses to guide health policies. The aim of this literature review was to evaluate the evidence regarding HRQoL following different management strategies for localised RCC.

Methods Three databases were searched to identify studies reporting HRQoL in patients with localised renal cancer, including Medline, the Tuft's Medical Centre Cost Effectiveness Analysis registry and the EuroQol website.

Results Considerable methodological heterogeneity was noted. Laparoscopic nephrectomy was associated with significantly better short-term physical function compared to open surgery, although the effect on mental function was inconclusive. Nephron-sparing surgery was associated with better physical function compared to radical surgery. Patients' perception of remaining renal function was a significant independent predictor of HRQoL, rather than surgery type. Tumour size, stage, post-operative complications, age, body mass index, occupational status, educational level and comorbidities were significant predictors of HRQoL. Only three studies were available regarding non-surgical management options and very little data were available regarding the impact of follow-up protocols and long-term effects of "cancer survivorship."

Conclusion There is a need for validated and reproducible RCC-specific HRQoL instruments and standardisation amongst studies to enable comparisons. Increased awareness regarding determinants of poor HRQoL may enable high-risk patients to receive tailored support.
\end{abstract}

Keywords Localised renal cell carcinoma $\cdot$ Quality of life $\cdot$ Utility $\cdot$ Nephrectomy $\cdot$ Review

Abbreviations

AS

CARE

CARES-SF
Active surveillance

Convalescence and Recovery

Evaluation

Cancer Rehabilitation Evaluation

System-Short Form
DISSRM

EASE

EORTC-QLQ-C30

EQ-5D

FACT-G

Electronic supplementary material The online version of this article (https://doi.org/10.1007/s00345-018-2415-3) contains supplementary material, which is available to authorized users.

Sabrina H. Rossi

sr725@cam.ac.uk

1 Academic Urology Group, University of Cambridge, Addenbrooke's Hospital, Cambridge Biomedical Campus, Box 43, Hills Road, CB2 0QQ Cambridge, UK

2 Department of Urology, Royal Bournemouth and Christchurch Hospitals, Bournemouth, UK

\section{FKSI}

GHQ

HADS

HRQoL

IES-R

LPN
Delayed Intervention and Surveillance for Small Renal Masses European Active SurveillancE of renal cell carcinoma study

European Organization for Research and Treatment of Cancer-Quality of Life Questionnaire-C30

EuroQol questionnaire

Functional Assessment of Cancer Therapy-General

Functional Assessment of Cancer Therapy-Kidney Symptom Index General Health Questionnaire Hospital Anxiety and Depression Scale Health-related quality of life Impact of Events Scale-Revised Laparoscopic partial nephrectomy 


$\begin{array}{ll}\text { LRN } & \text { Laparoscopic radical nephrectomy } \\ \text { MCS } & \text { Mental component score on SF-36 } \\ \text { MUIS } & \text { Mishel Uncertainty in Illness Scale } \\ \text { NICE } & \text { National Institute for Health and } \\ & \text { Care Excellence } \\ \text { NR } & \text { Not reported } \\ \text { NSS } & \text { Nephron-sparing surgery } \\ \text { OPN } & \text { Open partial nephrectomy } \\ \text { ORN } & \text { Open radical nephrectomy } \\ \text { PCS } & \text { Physical component score on SF-36 } \\ \text { PROMs } & \text { Patient reported outcome measures } \\ \text { PT } & \text { Primary treatment } \\ \text { QoL } & \text { Quality of life } \\ \text { RCC } & \text { Renal cell carcinoma } \\ \text { RCC-SI } & \text { Renal Cell Carcinoma-Symptom } \\ & \text { Index } \\ \text { RQRC } & \text { Rehabilitation Questionnaire for } \\ & \text { Renal Cancer } \\ \text { RRN } & \text { Retroperitoneoscopic radical } \\ & \text { nephrectomy } \\ \text { SF-12 } & \text { Short Form 12 } \\ \text { SF-36 } & \text { Short Form 36 } \\ \text { SPQ } & \text { Social Problem Questionnaire } \\ \text { VAS } & \text { Visual Analogue Scale }\end{array}$

\section{Introduction}

The incidence of renal cell carcinoma (RCC) is rising in Western Countries and is projected to rise further due to the aging population and rising prevalence of obesity [1]. As a result, a larger number of patients with RCC will require treatment annually, and live with the long-term sequelae of a cancer diagnosis. Due to the widespread use of abdominal imaging, a large proportion of individuals have small localised tumours, with excellent oncologic outcomes [2,3]. As such, there has been a shift towards maximising healthrelated quality of life (HRQoL) and preserving renal function. Indeed, surveys of patients affected by RCC consistently highlight the need to place more emphasis on HRQoL, improved patient-doctor communication, patient information and education and support following a cancer diagnosis [4, 5]. A systematic review published in 2012 assessing quality of life $(\mathrm{QoL})$ in patients undergoing management for localised RCC commented on the general lack of data, in particular concerning non-surgical management, with outcomes being inconsistently defined, measured and reported [6-8]. Since then, the urological community has acknowledged the importance of quantifying and maximising quality of life in patients with localised RCC, paralleled by an increasing in the number of publications regarding HRQoL and tools/questionnaires utilised for this purpose [9-11]. A greater understanding of HRQoL outcomes associated with different management options for RCC facilitates patient centred care and shared decision making. Additionally, there is an increasing emphasis on performing cost effectiveness analyses to quantify the incremental costs and quality adjusted life years of interventions in the diagnosis and management of RCC in the context of limited resources, to guide health policy.

This literature review describes key definitions and tools used to assess HRQoL outcomes in patients with localised $\mathrm{RCC}$, as well as applications to health economic evaluation. In addition, we summarise the key evidence regarding HRQoL following available management options, including laparoscopic and open radical nephrectomy (LRN and ORN), laparoscopic and open partial nephrectomy (LPN and OPN), ablation and active surveillance (AS).

\section{Methods}

The Medline database was searched to identify quality of life studies for localised RCC (updated to March 2018). The following keywords and medical subject headings were utilised: quality of life, EuroQol, nephrectomy, renal cell carcinoma, kidney cancer, renal mass, renal carcinoma and renal cancer. The search strategy was limited to English language studies. Where reviews were identified, the reference list was manually searched by the study authors. Furthermore, as quality of life studies are often utilised in health economic evaluation, the Tuft's Medical Centre Cost Effectiveness Analysis registry was searched to identify studies reporting QoL in patients with localised renal cancer. Lastly, the EuroQol website was searched to identify studies using the EQ-5D by searching for any publications containing the key words "kidney" or "renal", as this is the preferred questionnaire to assess utilities by the National Institute for Health and Care Excellence (NICE) [12].

\section{Results}

The search identified 31 studies within the Tuft's Medical Centre Cost Effectiveness Analysis registry. The EQ-5D website revealed 164 studies containing the key words "kidney" or "renal"; however, only one was pertinent to renal cancer. Overall, including the Medline search, a total of 61 full texts were reviewed. A number of methodological considerations were noted regarding the studies identified by this review. A number of different quality of life questionnaires and outcomes were reported, and there was a wide variation in the time point assessed (ranging from a few weeks to many years following management of renal cancer). Only one randomised control trial was identified, some studies were prospective in nature although the majority 
were retrospective. Most studies contained a small sample size including a heterogeneous study population and low response rates and were underpowered to detect differences in QoL between interventions and to assess determinants of QoL. Furthermore, a number of studies did not assess QoL at baseline prior to intervention, therefore, reducing the meaningfulness of comparisons between intervention types. As a result, there is a large degree of heterogeneity amongst studies, which limits our ability to pool and directly compare data.

\section{Definitions and instruments}

HRQoL is a multidimensional concept which is difficult to characterise and has, therefore, been associated with a myriad of varying definitions in the medical literature [13, 14]. Although QoL and HRQoL are often used interchangeably in the literature, HRQoL is specific to the patient's perception of the disease, including the diagnosis, symptoms, treatment and prognosis $[13,14]$. This encompasses physical, emotional, cognitive and social components, including the individual's functioning and wellbeing. QoL is a broader concept and is affected not only by health, but by other domains such as housing, employment, safety and freedom [15]. Both QoL and HRQoL are subjective measures which can be assessed in a validated and reproducible way through questionnaires of patient reported outcome measures (PROMs). PROMs are defined as measures which are directly reported by patients, without interpretation by a health care professional and refer to the method in which HRQoL is assessed rather than the content itself [15].

A number of generic and cancer-specific instruments have been developed to assess health-related QoL in patients with cancer and more specifically, patients with RCC (Table 1). Disease-specific questionnaires for patients with localised disease assess symptoms such as flank pain and haematuria, as well as more general cancer symptoms such as weight loss and fatigue [6]. Comparative studies evaluating different RCC-specific questionnaires have demonstrated that generally very similar symptoms are assessed, with the main differences being questionnaire phrasing, length and ease of use [16]. Questionnaires assess different domains of QoL and there is a fine balance between collecting adequate data regarding all domains and maintaining the instrument brief and practical.

\section{Surgical management}

\section{Laparoscopic versus open surgery}

It is widely recognised that the laparoscopic approach has a significant impact on reducing patients' hospital stay and return to daily activities [17]. A number of studies have evaluated whether this translates into a measurable quality of life benefit (Table 2). Burgess et al. performed a randomized control trial of laparoscopic versus open nephrectomy. The laparoscopic approach was associated with significantly reduced post-operative visual analogue pain scores and faster return to normal daily activities (42 vs 62 days; $p=0.04$ ). However, no significant difference was noted between EQ-5D scores in the two groups at 3 and 12 months post-operatively [18]. Parker et al. demonstrated that patients undergoing laparoscopic renal surgery had significantly better physical component scores (PCS) on SF-36 questionnaires compared to those undergoing open surgery, and return to baseline was quicker. However, although benefits on physical components were evident in the short term for patients undergoing LRN, the differences between laparoscopic and open surgery disappeared after a few months. Additionally, mental component scores (MCS) on SF-36 and Impact of Event Scale scores (IES), assessing intrusive thoughts and avoidance behaviour, were not significantly different [19]. Similarly, Acar et al. demonstrated shorter hospital stay, earlier ambulation and better general health perception following laparoscopic surgery. Following both laparoscopic and open surgery, by 6 months physical function scores were improved and were better than baseline [20]. Additionally, Harryman et al. suggested that the laparoscopic approach was associated not only with higher physical but also a significantly higher mental component score on SF-36 in the short-term post-operative period [21].

\section{Nephron-sparing vs radical surgery}

The impact of nephron-sparing surgery (NSS) compared to radical nephrectomy (RN) on HRQoL scores is multilayered and remains somewhat unclear. The aim of NSS is to preserve renal function and several studies suggest that preserved glomerular filtration rate is associated with measurable benefits in patient-reported HRQoL (Table 2). Clark et al. evaluated individuals with localised renal tumours undergoing RN and PN. Patients' perception of remaining renal function was a significant and independent predictor of HRQoL, rather than surgery type. Patients who self-reported as having less remaining renal parenchyma had significantly worse physical health on SF-36, higher intrusion and avoidance scores on IES, and more negative thoughts regarding cancer recurrence or reduced renal function [22]. Several studies demonstrated similar findings: patients undergoing RN had more worry regarding potential loss or damage to the single functioning contralateral kidney $[19,23]$. Furthermore, several studies demonstrate that PN is associated with significantly better physical function scores compared to $\mathrm{RN}$, as well as reduced symptoms such as fatigue, sleep disturbance and pain [24-26]. Ficarra et al. report that levels of anxiety 
Table 1 Generic and cancer-specific instruments which have been utilised to assess health-related quality of life in renal cancer

Instrument Description

Generic instruments assessing quality of life

RAND medical outcome survey Short Form 36 (SF-36) and Short Form 12 (SF-12) [52]

EuroQol (EQ-5D) [53]

Convalescence and Recovery Evaluation (CARE) [54]

Cancer-specific instruments assessing quality of life

Cancer Rehabilitation Evaluation System-Short Form (CARES-SF) [55]

European Organization for Research and Treatment of Cancer (EORTC) Quality of Life Questionnaire (QLQ) C30 [56]

Functional Assessment of Cancer Therapy-General (FACT-G) [57]

Functional Assessment of Cancer Therapy-Kidney Symptom Index (FKSI) $[58,59]$

Renal Cell Carcinoma-Symptom Index (RCC-SI) [60]

Instruments to assess psychological wellbeing

Impact of Events Scale (IES) [61]

Hospital Anxiety and Depression Scale (HADS) [62]

Mishel Uncertainty in Illness Scale (MUIS) [63]
SF-36 is a questionnaire with 36 multiple choice items. Eight domains are assessed and two summary scores are produced (physical and mental component summary scores). The eight domains are: physical function, role limitations due to physical health problems, bodily pain, general health perception, emotional wellbeing, role limitations due to emotional problems, energy/fatigue, and social function. A shortened version has been developed, the SF-12, which can be completed in a third of the time as it only contains 12 items. Results from the SF-36 and SF-12 can be classified according to the SF-6D, which allows preference based health state utilities to be derived for health economic evaluation

The EuroQol questionnaire contains five dimensions: mobility, selfcare, usual activities, pain/discomfort and anxiety/depression. For adults, two versions exist; the EQ-5D-5L which contains five levels for each of the five domains and the EQ-5D-3L which contains three levels. According to NICE guidelines, the recommended method to assess utilities is using the EQ-5D questionnaire [12]

This questionnaire was designed to assess short term physical and cognitive function following abdominopelvic surgery. It contains 27 items and four domains: pain, gastrointestinal, cognitive, and activity

Cancer-specific quality of life questionnaire containing five domains: physical, psychosocial, medical, sexual functioning and marital

General quality of life questionnaire used in different cancer types designed to assess QoL in clinical oncology trials. The questionnaire assesses global QoL, symptom scales and five functional scales (physical, role, cognitive, emotional, and social). A renal cancer-specific domain has recently been developed, although it remains to be externally validated [6]. This includes the following disease-specific items: flank pain, oedema, haematuria and urinary tract infections [6]

The FACT-G questionnaire contains core domains and can be used in all cancer types, including renal cancer. The following domains are assessed: physical wellbeing, social/family wellbeing, emotional wellbeing, and functional wellbeing. A number of disease-specific modifications exist, which are pertinent to advanced RCC (see below)

The FKSI is used in individuals with advanced renal cancer to assess disease-related symptoms, treatment side effects, and general function and wellbeing. A number of variations/subsets have been published, each containing a different number of items. The FKSI15 contains 15 items, the FSKI-19 contains 19 items, while the FKSI-Disease Related Symptoms (FKSI-DRS) focuses specifically on disease-related, rather than treatment-related quality of life. For example the FKSI-DRS assesses haematuria, fevers, chest symptoms, bone pain and fatigue

This questionnaire assesses renal cancer-specific physical and psychological symptoms and can be used in both localised and advanced renal cancer. Items assessed include: haematuria, difficulty passing urine, pain, chest and bowel symptoms, sleep and fatigue

Questionnaire to assess distress by evaluating two domains: intrusive thoughts and avoidance behaviour

This questionnaire contains 14 multiple choice questions assessing anxiety and depression

This consists of four domains regarding diagnosis, treatment, disease severity and outcomes: ambiguity, complexity, lack of information and unpredictability 


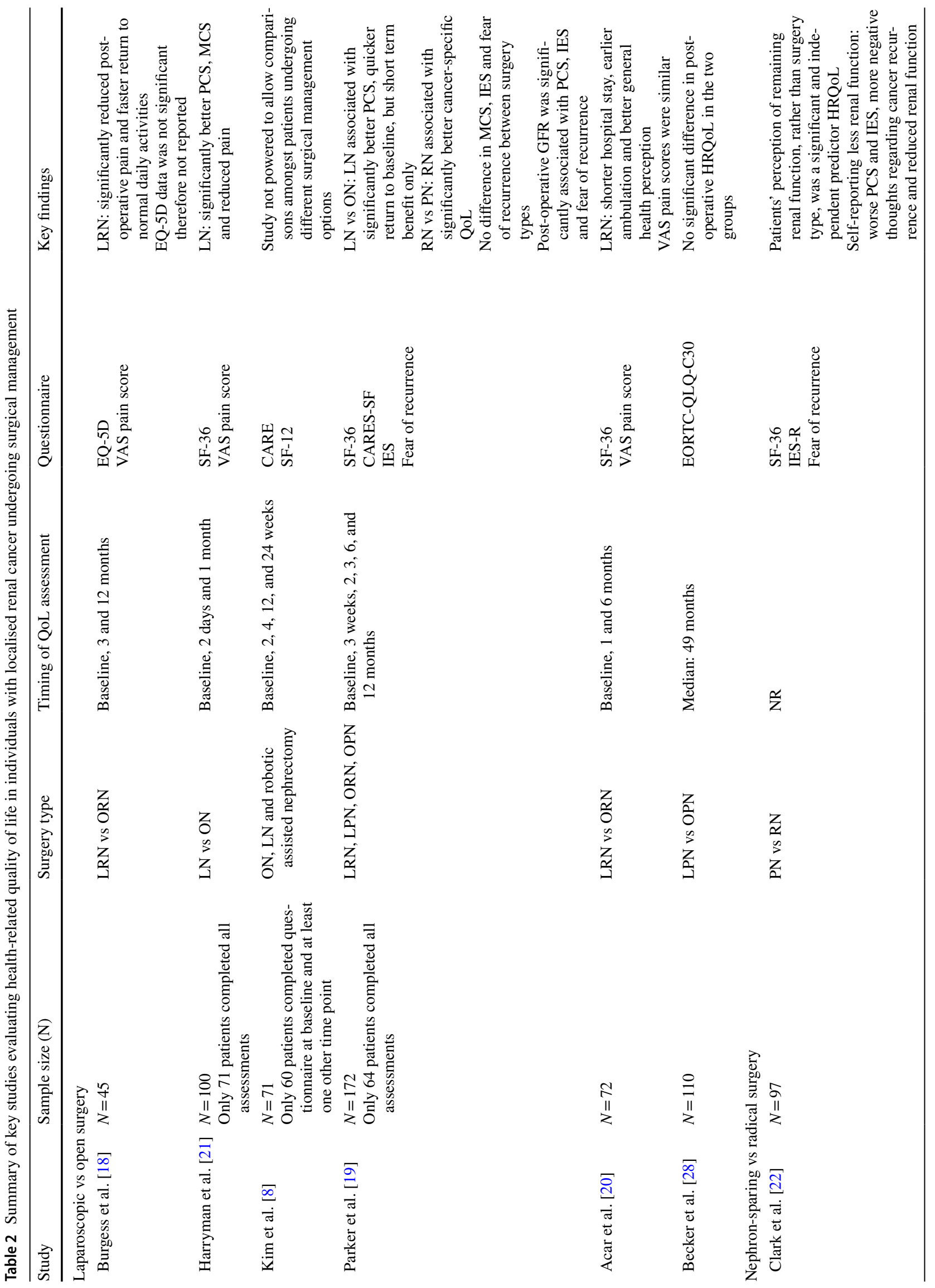




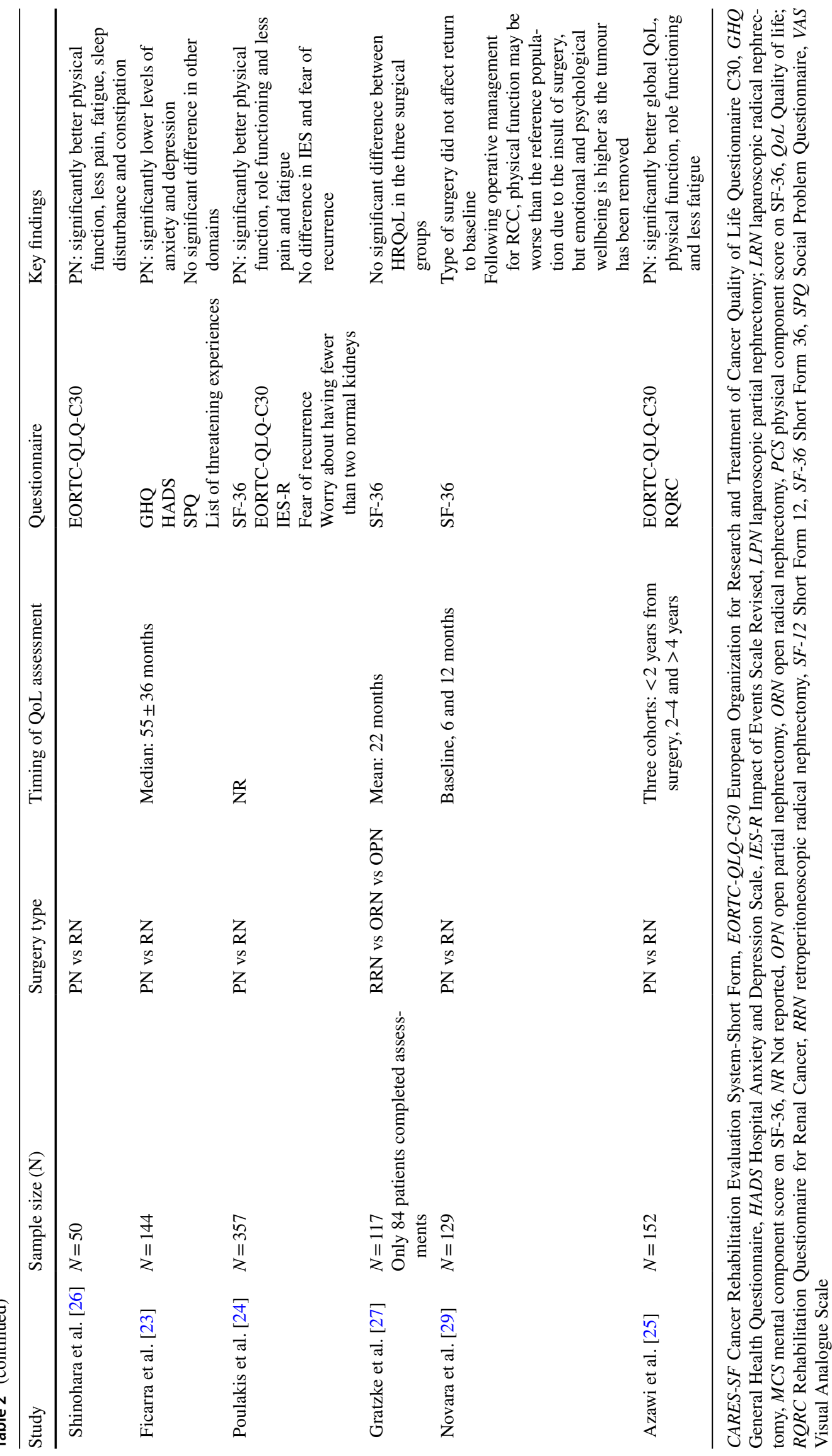


and depression in patients undergoing $\mathrm{RN}$ and $\mathrm{PN}$ are very low, however significantly lower in the PN group [23]. However, some inconsistencies remain. Parker et al. demonstrated better cancer-specific QoL in patients who underwent RN compared to PN [19]. In addition, a number of studies have failed to show a significant difference in quality of life following $\mathrm{RN}$ versus $\mathrm{PN}$, though this may be related to low sample size or the timing of the assessment in relation to surgery [27].

\section{Recovery following surgical management}

A number of studies suggest that HRQoL returns to baseline following surgical management of localised RCC and evaluate temporal trends (Table 2). Gratzke et al. assessed HRQoL using the SF-36 questionnaire in patients with stage I and stage II RCC following retroperitoneoscopic radical nephrectomy, open RN and open PN. There was no significant difference between HRQoL in the three surgical groups and physical condition scores in RCC patients 1 year following surgery were actually higher than an age- and sex-matched reference population [27]. This may be because operative candidates are more likely to be fitter and less comorbid than age- and sex-matched controls from the general population. Similarly, Becker et al. demonstrated that there was no significant difference in postoperative HRQoL in patients with stage I disease undergoing laparoscopic or open PN. Renal cancer patients' HRQoL scores were either better or the same for males and females, respectively, compared to a German reference population [28]. Kim et al. evaluated the Convalescence and Recovery Evaluation (CARE) and SF-12 preoperatively and following open, laparoscopic and robotic renal surgery $(2,4,12$, and 24 weeks post-operatively). A temporal trend was observed in HRQoL outcomes: over half of patients returned to baseline by 4 weeks and over $80 \%$ of patients returned to baseline HRQoL by 12 weeks post-operatively. Unfortunately, the study was underpowered and did not allow comparisons amongst patients undergoing different surgical management [8]. Novara et al. compared SF-36 scores in patients undergoing NSS or RN. Baseline pre-operative scores were not significantly different between individuals with RCC and the age- and sex-matched reference population. The study showed that approximately $50-80 \%$ of patients returned to baseline at 24 and 52 weeks post-operatively. Furthermore, it was suggested that following operative management for $\mathrm{RCC}$, physical function may be worse than the reference population due to the insult of surgery, but emotional and psychological wellbeing is higher as the tumour has been removed [29]. In contrast, Parker et al. suggest that following laparoscopic surgery, the observed reduction in physical scores on HRQoL improve by 3 months; however, anxiety and worry regarding cancer recurrence remain long term [19].

\section{Determinants of post-operative HRQoL}

Identifying determinants of poor HRQoL outcomes is crucial to enable the identification of high-risk groups, which would benefit from additional psychological and physical support. Unsurprisingly, patients with recurrence have significantly worse HRQoL. Furthermore, individuals with more advanced tumour size and pathological stage experience significantly greater fear of recurrence, intrusive thoughts, hyperarousal and avoidance behaviour [24]. Patients with a low pre-operative renal function or single kidney undergoing "imperative" NSS have significantly increased worry regarding cancer recurrence and worsening renal function, compared to individuals undergoing "elective" NSS [22, 24]. Individuals undergoing "imperative" NSS are also significantly less likely to return to baseline social and physical function on SF-36 scores post-operatively compared to individuals undergoing "elective" surgery [29].

Complications following renal surgery are a major determinant of HRQoL [27]. This is a well-documented effect, and a recently performed meta-analysis demonstrated that across all surgical specialities, post-operative complications are associated with decreased physical, social and emotional wellbeing. Most importantly, there was a discrepancy between the reported severity of complications by health care professionals and patients, meaning that even what may be perceived as mild complications can have a profound impact on the patients' recovery [30]. Age is an established determinant of QoL following operative management. Increasing age is associated with longer time to return to baseline physical function, higher fear of recurrence but less intrusive thoughts and avoidance behaviour [19, 29]. As expected, body mass index, occupational status, educational level and comorbidities were significantly associated with return to baseline QoL assessments on the SF-36 at 6 months and 1 year following operative management [29].

\section{Non-surgical management}

Data regarding the quality of life of patients undergoing nonsurgical management are sparse [31]. Onishi et al. performed a small trial $(n=37)$ comparing QoL using SF-36 questionnaire in patients undergoing percutaneous radiofrequency ablation (RFA) and LRN [32]. Patients undergoing RFA were significantly older and had significantly worse baseline HRQoL compared to individuals undergoing LRN, reflecting inherent differences in the two populations. As expected, LRN was associated with a post-operative HRQoL decrement in physical functioning, role-physical functioning and role-emotional functioning, which resolved by $4-11$ weeks. 
Patients undergoing RFA did not experience a decrement in HRQoL following the procedure and on the contrary, perceived a steady increase in HRQoL in role-physical functioning, vitality and mental health. RFA remains an excellent alternative for patients with small renal masses who opt not to undergo NSS due to comorbidities or patient choice. However, more data are required to evaluate the long-term impact of tumour recurrence and the need for repeat RFA interventions on patients' HRQoL, in a larger patient cohort.

Parker et al. evaluated HRQoL in 100 patients with clinically $\mathrm{T} 1$ and $\mathrm{T} 2$ renal masses undergoing active surveillance over a 24-month period. As time progressed, there was a significant worsening in the physical component of the SF-36, but a reduction in intrusive thoughts on IES. Illness uncertainty was a significant predictor of overall and cancer-specific HRQoL scores and HRQoL was significantly predicted by age, gender, renal function, tumour size and comorbidities [33]. Unfortunately, the study did not compare HRQoL in patients undergoing different treatment options. More recently, Patel et al. evaluated 539 patients with small renal masses (clinically T1a) enrolled in the prospective, multi-centre Delayed Intervention and Surveillance for Small Renal Masses (DISSRM) Registry [34]. Patients were offered the choice between AS and primary treatment (PT). Patients undergoing AS were nearly 10 years older and had more comorbidities at baseline than patients choosing PT. Over the observation period, PCS scores on SF-12 worsened similarly with time in both PI and AS groups; however, PCS remained significantly worse in the AS group compared to PT group at all time points, reflecting the initial poorer overall health and comorbidities. Comorbidities, as measured by Eastern Cooperative Oncology Group performance status and cardiovascular index, were significant predictors of HRQoL. Most importantly, AS (and crossing over from AS to treatment) was not associated with a reduction in MCS scores compared to PT. In itself, shared decision making between patients with cancer and health care professionals regarding treatment choices has been shown to increase HRQoL [35]. Similarly, studies in patients undergoing AS or PT for prostate cancer have also failed to show a significant association between AS and reduced HRQoL [36].

\section{Follow-up and surveillance}

The optimal evidence-based follow-up protocol for patients with localised RCC who have undergone curative treatment has yet to be defined. Follow-up recommendations from different urological societies are conflicting; however, broadly it is recommended for patients to undergo annual abdominal \pm chest imaging for several years based on prognostic risk [37]. Patients may experience increased anxiety in relation to continued investigations, especially in the context of time delays between undergoing imaging and receiving results. A recently performed systematic review of studies assessing HRQoL in patients with colorectal cancer undergoing regular follow-up suggested that over a third of studies reported negative perceptions of follow-up, including increased anxiety and stress [38]. There is a lack of data regarding the impact of follow-up protocols on HRQoL and patient preferences in RCC.

Kent et al. assessed long-term HRQoL in patients defined as "cancer survivors." The mean interval after RCC diagnosis was 77 months. Although the stage of the disease was not reported, patients with RCC had significantly worse PCS but similar MCS compared to individuals from the general population. Overall, scores for RCC survivors were similar to that of other cancers [39]. Sexual function may play an important role in patients' QoL; however, this domain is often overlooked by health care professionals. There has been some suggestion that RCC survivors may have relatively poor sexual functioning compared to breast cancer survivors [40]. More research is required in this field [5].

\section{HRQoL and cost utility analyses}

HRQoL has also arisen as a key component of cost utility analyses and economic evaluation. In the context of a finite healthcare budget, decisions need to be made regarding which interventions can be preferentially funded; thus, there is a drive to assess not only effectiveness but also cost effectiveness of interventions [41]. Cost utility analyses evaluate costs and quality adjusted life years (QALYs), a measure of length and quality of life, enabling a range of interventions to be compared against each other [41]. A large number of cost utility analyses have been undertaken to evaluate systemic therapies in metastatic RCC and more recently there has been a rise in the number of analyses performed to evaluate management options in localised disease [42-47]. An understanding of how utilities are derived highlights key challenges in this field. Utilities consist of preference-based values that are applied to health states [48]. Perfect health is associated with a utility of 1 and death of 0 , although some conditions may be worse than death and, therefore, associated with a negative value. More desirable or preferable utilities are associated with higher values on this scale. To derive utilities, patients with the condition of interest are asked to fill in HRQoL questionnaires, such as the EQ-5D, SF-36 or EORTC-QLQ-C30. Individuals from the general public are subsequently asked to assign relative values or preferences to each of the health states reported by the patients, based on methods such as standard gamble, time trade-off, or Visual Analogue Scale [49]. Clearly, the results of a cost utility analysis are dependent on the accuracy of the HRQoL studies and country-specific value sets used to determine the utilities. Due to the lack of existing evidence, earlier cost effectiveness analyses estimated health state 
utilities for localised RCC based on clinical expert judgment and data from other disease areas, such as colorectal cancer [42, 43, 46, 47]. More recently, Chang et al. estimated a health state utility of 0.7 for OPN and 0.88 for LPN relative to perfect health; however, the study did not describe the methods used to derive these values [44]. Klinghoffer et al. calculated health state utilities for individuals undergoing LRN and OPN based on the results of SF-36 questionnaire mapped to utility values (utility for LRN: 0.73; utility for OPN: 0.744) [45]. However, utilities were estimated for LPN as no data were available, and robotic and ORN surgery were not included in the analysis. This highlights a lack of data regarding utilities for localised RCC and demonstrates a clear priority for further research.

\section{Critical review and future directions}

Despite increases in the number of studies reporting HRQoL in localised RCC in recent years, a number of methodological considerations remain. A variety of different questionnaires are used, limiting the ability to compare results across studies. Although the majority of studies utilise the SF-36, it has been postulated that such generic questionnaires do not accurately capture RCC-specific QoL [6]. More recently, there has been a drive to develop RCC-specific HRQoL questionnaires, aimed at patients with localised disease; however, these are not yet used routinely in clinical studies [6]. There is a need for validated and reproducible renal cancer-specific HRQoL instruments, and standardisation amongst studies to enable comparisons [50].

A number of areas were identified in which further HRQoL research is necessary. Notably, there was a lack of data regarding robotic surgery, as studies were underpowered to report on this, as well as ablation and AS. The European Active SurveillancE of Renal cancer (EASE) study is currently underway and it will provide crucial information regarding $\mathrm{HRQ} O \mathrm{~L}$ in patients undergoing $\mathrm{AS}$, as measured by EORTC QLQ-C30 and HADS questionnaires [51]. Future studies assessing management strategies for localised RCC should routinely report PROMs. More research is also required regarding the long-term impact of "cancer survivorship" in patients with RCC, including the impact on sexual function [5]. We identified only two studies reporting utilities in localised RCC based on HRQoL, and methods were incompletely reported. There is, therefore, a need for transparent studies evaluating HRQoL and mapping these to health state utility values to enable cost effectiveness analyses in localised RCC.

\section{Conclusion}

In summary, laparoscopic nephrectomy was associated with significantly better short-term physical function compared to open surgery, although the effect on mental function was inconclusive. The effect of NSS on HRQoL was less clear cut. Overall, it was suggested that NSS was associated with better physical function as well as reduced intrusive thoughts, avoidance behaviour, anxiety and worry. Ablative therapy and AS were not associated with worse psychological outcomes compared to operative management, though data were sparse.

This review highlights the importance of assessing HRQoL in patients undergoing management for localised RCC. This may enhance patient centred care and shared decision making as well as enabling more accurate health economic evaluations to guide health policy. Further education is required amongst renal cancer surgeons to increase awareness regarding determinants of poor HRQoL following management for RCC. This will enable patients at high risk of worse HRQoL to be identified and offered tailored support, including psychological interventions and increased education. Further education may also help us to overcome the well-documented discrepancies between health care professionals and patient perception of the cancer consultation [5].

Acknowledgements We would like to acknowledge The Urology Foundation, who kindly provided a research grant for SHR.

Author contributions SR: Project development, data collection, data analysis, manuscript writing and editing. TK: project development, manuscript writing and editing. GDS: project development, data analysis, manuscript editing.

\section{Compliance with ethical standards}

Conflict of interest The authors declare that they have no relevant conflict of interest.

Research involving human participants and/or animals The following manuscript is a review of existing data. Therefore, this article does not contain any studies with human participants or animals performed by any of the authors.

Informed consent For this type of study (review) formal consent is not required.

Open Access This article is distributed under the terms of the Creative Commons Attribution 4.0 International License (http://creativeco mmons.org/licenses/by/4.0/), which permits unrestricted use, distribution, and reproduction in any medium, provided you give appropriate credit to the original author(s) and the source, provide a link to the Creative Commons license, and indicate if changes were made. 


\section{References}

1. Rossi SH, Klatte T, Usher-Smith J, Stewart GD (2018) Epidemiology and screening for renal cancer. World J Urol. https://doi. org/10.1007/s00345-018-2286-7

2. Cancer Research UK (2016) Five-year relative survival by stage, adults (aged 15-99 years), former anglia cancer network, 20022006. http://www.cancerresearchuk.org/health-professional/cance r-statistics/statistics-by-cancer-type/kidney-cancer/survival\#headi ng-Three. Accessed 26 July 2016

3. Simone G, Tuderti G, Anceschi U, Papalia R, Ferriero M, Misuraca L, Minisola F, Mastroianni R, Costantini M, Guaglianone S, Sentinelli S, Gallucci M (2017) Oncological outcomes of minimally invasive partial versus minimally invasive radical nephrectomy for cT1-2/N0/M0 clear cell renal cell carcinoma: a propensity score-matched analysis. World J Urol 35(5):789794. https://doi.org/10.1007/s00345-016-1923-2

4. The Kidney Cancer UK patient survey report 2018 (2018). https ://www.kcuk.org.uk/wp-content/uploads/2018/01/2018-Kidne y-Cancer-UK-Patient-Survey-Report-1.pdf. Accessed Mar 2018

5. Moretto P, Jewett MA, Basiuk J, Maskens D, Canil CM (2014) Kidney cancer survivorship survey of urologists and survivors: the gap in perceptions of care, but agreement on needs. Can Urol Assoc J 8(5-6):190-194. https://doi.org/10.5489/cuaj.1907

6. Beisland E, Aarstad HJ, Aarstad AK, Bakke A, Bostad L, Beisland C (2016) Development of a disease-specific health-related quality of life (HRQoL) questionnaire intended to be used in conjunction with the general European Organization for Research and Treatment of Cancer (EORTC) Quality of Life Questionnaire (QLQ) in renal cell carcinoma patients. Acta Oncol 55(3):349-356. https ://doi.org/10.3109/0284186X.2015.1063776

7. MacLennan S, Imamura M, Lapitan MC, Omar MI, Lam TB, Hilvano-Cabungcal AM, Royle P, Stewart F, MacLennan G, MacLennan SJ, Dahm P, Canfield SE, McClinton S, Griffiths TR, Ljungberg B, N'Dow J, Group USRR, Panel EAURCG (2012) Systematic review of perioperative and quality-of-life outcomes following surgical management of localised renal cancer. Eur Urol 62(6):1097-1117. https://doi.org/10.1016/j.eururo.2012.07.028

8. Kim SB, Williams SB, Cheng SC, Sanda MG, Wagner AA (2012) Evaluation of patient-reported quality-of-life outcomes after renal surgery. Urology 79(6):1268-1273. https://doi.org/10.1016/j.urolo gy.2012.02.047

9. Mehran R, Baber U, Dangas G (2018) Guidelines for patientreported outcomes in clinical trial protocols. JAMA 319(5):450 451. https://doi.org/10.1001/jama.2017.21541

10. Bingener J, Sloan J, Boughey JC (2014) Patient quality of life: vitally important. Bull Am Coll Surg 99(5):46-48

11. Pierorazio PM, Johnson MH, Patel HD, Sozio SM, Sharma R, Iyoha E, Bass EB, Allaf ME (2016) Management of renal masses and localized renal cancer: systematic review and meta-analysis. $\mathrm{J}$ Urol 196(4):989-999. https://doi.org/10.1016/j.juro.2016.04.081

12. National Institute for Health and Care Excellence (NICE) (2013) Guide to the methods of technology appraisal. https://www.nice. org.uk/process/pmg9. Accessed 7 Dec 2017

13. Karimi M, Brazier J (2016) Health, health-related quality of life, and quality of life: what is the difference? Pharmacoeconomics 34(7):645-649. https://doi.org/10.1007/s40273-016-0389-9

14. Bottomley A (2002) The cancer patient and quality of life. Oncologist 7(2):120-125

15. Patrick DL, Burke LB, Powers JH, Scott JA, Rock EP, Dawisha S, O’Neill R, Kennedy DL (2007) Patient-reported outcomes to support medical product labeling claims: FDA perspective. Value Health 10(Suppl 2):S125-S137. https://doi.org/10.111 1/j.1524-4733.2007.00275.x
16. Rao D, Butt Z, Rosenbloom S, Robinson D Jr, Von Roenn J, Kuzel TM, Cella D (2009) A comparison of the renal cell carcinoma-symptom index (RCC-SI) and the functional assessment of cancer therapy-kidney symptom index (FKSI). J Pain Symptom Manage 38(2):291-298. https://doi.org/10.1016/j.jpainsymma n.2008.08.013

17. Hadjipavlou M, Khan F, Fowler S, Joyce A, Keeley FX, Sriprasad S, Endourology BSo, Oncology (2016) Partial vs radical nephrectomy for T1 renal tumours: an analysis from the British association of urological surgeons nephrectomy audit. BJU Int 117(1):62-71. https://doi.org/10.1111/bju.13114

18. Burgess NA, Koo BC, Calvert RC, Hindmarsh A, Donaldson PJ, Rhodes M (2007) Randomized trial of laparoscopic v open nephrectomy. J Endourol 21(6):610-613. https://doi.org/10.1089/ end.2006.0277

19. Parker PA, Swartz R, Fellman B, Urbauer D, Li Y, Pisters LL, Rosser CJ, Wood CG, Matin SF (2012) Comprehensive assessment of quality of life and psychosocial adjustment in patients with renal tumors undergoing open, laparoscopic and nephron sparing surgery. J Urol 187(3):822-826. https://doi.org/10.1016/j. juro.2011.10.151

20. Acar C, Bilen C, Bayazit Y, Aslan G, Koni A, Basok E, Kaplan M (2014) Quality of life survey following laparoscopic and open radical nephrectomy. Urol J 11(6):1944-1950

21. Harryman OA, Davenport K, Keoghane S, Keeley FX, Timoney AG (2009) A comparative study of quality of life issues relating to open versus laparoscopic nephrectomy: a prospective pragmatic study. J Urol 181(3):998-1003. https://doi.org/10.1016/j. juro.2008.11.028 (discussion 1003)

22. Clark PE, Schover LR, Uzzo RG, Hafez KS, Rybicki LA, Novick AC (2001) Quality of life and psychological adaptation after surgical treatment for localized renal cell carcinoma: impact of the amount of remaining renal tissue. Urology 57(2):252-256

23. Ficarra V, Novella G, Sarti A, Novara G, Galfano A, Cavalleri S, Artibani W (2002) Psycho-social well-being and general health status after surgical treatment for localized renal cell carcinoma. Int Urol Nephrol 34(4):441-446

24. Poulakis V, Witzsch U, de Vries R, Moeckel M, Becht E (2003) Quality of life after surgery for localized renal cell carcinoma: comparison between radical nephrectomy and nephron-sparing surgery. Urology 62(5):814-820

25. Azawi NH, Tesfalem H, Dahl C, Lund L (2015) Do the different types of renal surgery impact the quality of life in the postoperative period? Int Urol Nephrol 47(2):263-269. https://doi. org/10.1007/s11255-014-0893-9

26. Shinohara N, Harabayashi T, Sato S, Hioka T, Tsuchiya K, Koyanagi $\mathrm{T}$ (2001) Impact of nephron-sparing surgery on quality of life in patients with localized renal cell carcinoma. Eur Urol 39(1):114-119. https://doi.org/10.1159/000052422

27. Gratzke C, Seitz M, Bayrle F, Schlenker B, Bastian PJ, Haseke N, Bader M, Tilki D, Roosen A, Karl A, Reich O, Khoder WY, Wyler S, Stief CG, Staehler M, Bachmann A (2009) Quality of life and perioperative outcomes after retroperitoneoscopic radical nephrectomy (RN), open RN and nephron-sparing surgery in patients with renal cell carcinoma. BJU Int 104(4):470-475. https ://doi.org/10.1111/j.1464-410X.2009.08439.x

28. Becker A, Pradel L, Kluth L, Schmid M, Eichelberg C, Ahyai S, Trinh Q, Seiler D, Dahlem R, Hansen J, Rink M, Zacharias M, Mehnert A, Bergelt C, Fisch M, Chun FK (2015) Laparoscopic versus open partial nephrectomy for clinical T1 renal masses: no impact of surgical approach on perioperative complications and long-term postoperative quality of life. World J Urol 33(3):421426. https://doi.org/10.1007/s00345-014-1318-1

29. Novara G, Secco S, Botteri M, De Marco V, Artibani W, Ficarra V (2010) Factors predicting health-related quality of life recovery in patients undergoing surgical treatment for renal tumors: 
prospective evaluation using the RAND SF-36 Health Survey. Eur Urol 57(1):112-120. https://doi.org/10.1016/j.eururo.2009.04.023

30. Pinto A, Faiz O, Davis R, Almoudaris A, Vincent C (2016) Surgical complications and their impact on patients' psychosocial well-being: a systematic review and meta-analysis. BMJ Open 6(2):e007224. https://doi.org/10.1136/bmjopen-2014-007224

31. Pierorazio PM, Johnson MH, Patel HD, Sozio SM, Sharma R, Iyoha E, Bass EB, Allaf ME (2016) Management of renal masses and localized renal cancer: systematic review and meta-analysis. J Urol. https://doi.org/10.1016/j.juro.2016.04.081

32. Onishi T, Nishikawa K, Hasegawa Y, Yamada Y, Soga N, Arima K, Yamakado K, Hoshina A, Sugimura Y (2007) Assessment of health-related quality of life after radiofrequency ablation or laparoscopic surgery for small renal cell carcinoma: a prospective study with medical outcomes Study 36-Item Health Survey (SF36). Jpn J Clin Oncol 37(10):750-754. https://doi.org/10.1093/ jjco/hym 107

33. Parker PA, Alba F, Fellman B, Urbauer DL, Li Y, Karam JA, Tannir N, Jonasch E, Wood CG, Matin SF (2013) Illness uncertainty and quality of life of patients with small renal tumors undergoing watchful waiting: a 2-year prospective study. Eur Urol 63(6):1122-1127. https://doi.org/10.1016/j.eururo.2013.01.034

34. Patel HD, Riffon MF, Joice GA, Johnson MH, Chang P, Wagner AA, McKiernan JM, Trock BJ, Allaf ME, Pierorazio PM (2016) A prospective, comparative study of quality of life among patients with small renal masses choosing active surveillance and primary intervention. J Urol 196(5):1356-1362. https://doi.org/10.1016/j. juro.2016.04.073

35. Victorson DE, Schuette S, Schalet BD, Kundu SD, Helfand BT, Novakovic K, Sufrin N, McGuire M, Brendler C (2016) Factors affecting quality of life at different intervals after treatment of localized prostate cancer: unique influence of treatment decision making satisfaction, personality and sexual functioning. J Urol 196(5):1422-1428. https://doi.org/10.1016/j.juro.2016.05.099

36. Wilcox CB, Gilbourd D, Louie-Johnsun M (2014) Anxiety and health-related quality of life (HRQL) in patients undergoing active surveillance of prostate cancer in an Australian centre. BJU Int 113(Suppl 2):64-68. https://doi.org/10.1111/bju.12557

37. Dabestani S, Marconi L, Kuusk T, Bex A (2018) Follow-up after curative treatment of localized renal cell carcinoma. World J Urol. https://doi.org/10.1007/s00345-018-2338-z (In press)

38. Berian JR, Cuddy A, Francescatti AB, O’Dwyer L, Nancy You Y, Volk RJ, Chang GJ (2017) A systematic review of patient perspectives on surveillance after colorectal cancer treatment. J Cancer Surviv 11(5):542-552. https://doi.org/10.1007/s1176 4-017-0623-2

39. Kent EE, Ambs A, Mitchell SA, Clauser SB, Smith AW, Hays RD (2015) Health-related quality of life in older adult survivors of selected cancers: data from the SEER-MHOS linkage. Cancer 121(5):758-765. https://doi.org/10.1002/cncr.29119

40. Anastasiadis AG, Davis AR, Sawczuk IS, Fleming M, Perelman MA, Burchardt M, Shabsigh R (2003) Quality of life aspects in kidney cancer patients: data from a national registry. Support Care Cancer 11(11):700-706. https://doi.org/10.1007/s0052 0-003-0484-2

41. Drummond M, Sculpher M, Claxton K, Stoddart G, Torrance G (2015) Methods for the Economic Evaluation of Health Care Programmes, 4th edn. Oxford University Press, Oxford

42. Abouassaly R, Yang S, Finelli A, Kulkarni GS, Alibhai SM (2011) What is the best treatment strategy for incidentally detected small renal masses? A decision analysis. BJU Int 108(8 Pt 2):E223E231. https://doi.org/10.1111/j.1464-410X.2011.10115.x

43. Heilbrun ME, Yu J, Smith KJ, Dechet CB, Zagoria RJ, Roberts MS (2012) The cost-effectiveness of immediate treatment, percutaneous biopsy and active surveillance for the diagnosis of the small solid renal mass: evidence from a Markov model. J Urol 187(1):39-43. https://doi.org/10.1016/j.juro.2011.09.055

44. Chang SL, Cipriano LE, Harshman LC, Garber AM, Chung BI (2011) Cost-effectiveness analysis of nephron sparing options for the management of small renal masses. J Urol 185(5):1591-1597. https://doi.org/10.1016/j.juro.2010.12.100

45. Klinghoffer Z, Tarride JE, Novara G, Ficarra V, Kapoor A, Shayegan B, Braga LH (2013) Cost-utility analysis of radical nephrectomy versus partial nephrectomy in the management of small renal masses: adjusting for the burden of ensuing chronic kidney disease. Can Urol Assoc J 7(3-4):108-113. https://doi. org/10.5489/cuaj.502

46. Bhan SN, Pautler SE, Shayegan B, Voss MD, Goeree RA, You JJ (2013) Active surveillance, radiofrequency ablation, or cryoablation for the nonsurgical management of a small renal mass: a cost-utility analysis. Ann Surg Oncol 20(11):3675-3684. https:// doi.org/10.1245/s10434-013-3028-0

47. Pandharipande PV, Gervais DA, Mueller PR, Hur C, Gazelle GS (2008) Radiofrequency ablation versus nephron-sparing surgery for small unilateral renal cell carcinoma: cost-effectiveness analysis. Radiology 248(1):169-178. https://doi.org/10.1148/radio 1.2481071448

48. Weinstein MC, Torrance G, McGuire A (2009) QALYs: the basics. Value Health 12(Suppl 1):S5-S9. https://doi.org/10.111 1/j.1524-4733.2009.00515.X

49. Devlin NJ, Shah KK, Feng Y, Mulhern B, van Hout B (2018) Valuing health-related quality of life: an EQ-5D-5L value set for England. Health Econ 27(1):7-22. https://doi.org/10.1002/ hec. 3564

50. Matin SF (2016) Kidney cancer: quality-of-life outcomes in patients with small renal masses. Nat Rev Urol 13(8):443-444. https://doi.org/10.1038/nrurol.2016.124

51. Volpe A (2016) European Active SurveillancE of Renal Cell Carcinoma study facts and figures. https://uroweb.org/wp-content/ uploads/EASE-Facts-figures-07-03-2017.pdf. Accessed Feb 2018

52. Ware JE Jr, Sherbourne CD (1992) The MOS 36-item short-form health survey (SF-36). I. Conceptual framework and item selection. Med Care 30(6):473-483

53. Brooks RG, Jendteg S, Lindgren B, Persson U, Bjork S (1991) EuroQol: health-related quality of life measurement. Results of the Swedish questionnaire exercise. Health Policy 18(1):37-48

54. Hollenbeck BK, Dunn RL, Wolf JS Jr, Sanda MG, Wood DP, Gilbert SM, Weizer AZ, Montie JE, Wei JT (2008) Development and validation of the convalescence and recovery evaluation (CARE) for measuring quality of life after surgery. Qual Life Res 17(6):915-926. https://doi.org/10.1007/s11136-008-9366-x

55. Schag CA, Ganz PA, Heinrich RL (1991) CAncer rehabilitation evaluation system-short form (CARES-SF). A cancer specific rehabilitation and quality of life instrument. Cancer 68(6):1406-1413

56. Aaronson NK, Ahmedzai S, Bergman B, Bullinger M, Cull A, Duez NJ, Filiberti A, Flechtner H, Fleishman SB, de Haes JC et al (1993) The European organization for research and treatment of cancer QLQ-C30: a quality-of-life instrument for use in international clinical trials in oncology. J Natl Cancer Inst 85(5):365-376

57. Cella DF, Tulsky DS, Gray G, Sarafian B, Linn E, Bonomi A, Silberman M, Yellen SB, Winicour P, Brannon J et al (1993) The functional assessment of cancer therapy scale: development and validation of the general measure. J Clin Oncol 11(3):570-579

58. Rothrock NE, Jensen SE, Beaumont JL, Abernethy AP, Jacobsen PB, Syrjala K, Cella D (2013) Development and initial validation of the NCCN/FACT symptom index for advanced kidney cancer. Value Health 16(5):789-796. https://doi.org/10.1016/j. jval.2013.04.015

59. Cella D, Yount S, Brucker PS, Du H, Bukowski R, Vogelzang N, Bro WP (2007) Development and validation of a scale to 
measure disease-related symptoms of kidney cancer. Value Health 10(4):285-293. https://doi.org/10.1111/j.1524-4733.2007.00183 . $\mathrm{x}$

60. Harding G, Cella D, Robinson D Jr, Mahadevia PJ, Clark J, Revicki DA (2007) Symptom burden among patients with renal cell carcinoma (RCC): content for a symptom index. Health Qual Life Outcomes 5:34. https://doi.org/10.1186/1477-7525-5-34
61. Horowitz M, Wilner N, Alvarez W (1979) Impact of event scale: a measure of subjective stress. Psychosom Med 41(3):209-218

62. Zigmond AS, Snaith RP (1983) The hospital anxiety and depression scale. Acta Psychiatr Scand 67(6):361-370

63. Mishel MH (1981) The measurement of uncertainty in illness. Nurs Res 30(5):258-263 